\title{
Susceptibility of cereal species to Fusarium langsethiae under identical field conditions
}

\author{
by Opoku, N., Back, M.A. and Edwards, S.G.
}

Copyright, Publisher and Additional Information: This is the author accepted manuscript. The final published version (version of record) is available online via Springer

Please refer to any applicable terms of use of the publisher.

DOI: https://dx.doi.org/10.1007/s10658-017-1329-Z

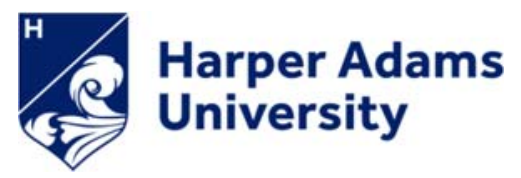

Opoku, N., Back, M.A. and Edwards, S.G. 2017. Susceptibility of cereal species to Fusarium langsethiae under identical field conditions. European Journal of Plant Pathology. 


\section{Susceptibility of cereal species to Fusarium langsethiae under identical field conditions}

3 Crop and Environment Sciences, Harper Adams University, Newport, Shropshire, UK

$4 \quad *$ Corresponding author: sedwards@ harper-adams.ac.uk

$5{ }^{1}$ Current Address: Department of Biotechnology, Faculty of Agriculture, University for

6 Development Studies, Tamale, Ghana
8

9

\section{Abstract}

Experiments were conducted to determine the extent of Fusarium langsethiae infection in wheat, barley and oats grown under identical experimental conditions. In total, four experiments were conducted with both winter and spring sown experiments at two locations. The amount of $F$. langsethiae infection was determined by quantifying $F$. langsethiae DNA and quantifying the combined concentration of the trichothecene mycotoxins HT-2 and T-2 (HT-2+T-2) in cereal head fractions (grain and rest of the head) after threshing at harvest. Results of the study showed that under identical experimental conditions, oats had the highest F. langsethiae DNA and HT-2+T-2 concentrations compared to wheat and barley. This indicates that the high levels detected on UK oats compared to wheat and barley from surveys of commercial crops is a consequence of genetic differences rather than differences in agronomy applied to the cereal species. The concentration of HT-2 and T-2 per unit of $F$. langsethiae DNA in oats compared to wheat and barley was also significantly higher indicating host differences in either the stimulation of HT-2 and T-2 production or in the metabolism of HT-2 and T-2. The study also showed that the proportion of $F$. langsethiae DNA in threshed grains was significantly lower than that in the rest of the cereal head.

Key words: cereal, wheat, barley, oats, HT-2, T-2, trichothecene, mycotoxin 


\section{Introduction}

Fusarium species can infect cereal crops resulting in the disease fusarium head blight and the contamination of cereal grains with fusarium mycotoxins. Fusarium species can produce numerous mycotoxins including several trichothecenes. The type A trichothecenes include the closely related mycotoxins HT-2 and T-2. A survey of commercial crops identified a high proportion of UK oats contained high concentrations of the mycotoxins HT-2 and T-2 (Edwards, 2007). It was subsequently determined that Fusarium langsethiae is the primary, if not sole, species responsible for this type of mycotoxin contamination (Edwards et al, 2009). There are currently no legal limits for these toxins but the European Commission has published a recommendation (Anon 2013) stating that these toxins should be monitored by Member States and where they exceed indicative levels, investigations should be performed as to why these high levels occur and what methods can be used to reduce the occurrence of these exceedances. The indicative level for unprocessed oats is $1000 \mu \mathrm{g} \mathrm{kg}^{-1}$ for the combined concentration of HT-2 and T-2 (HT-2+T-2). Surveys conducted from 2001-2008 identified that on average $16 \%$ of UK oats exceeded the indicative level of $1000 \mu \mathrm{g} \mathrm{kg}^{-1} \mathrm{HT}-2+\mathrm{T}-2$, whilst levels detected in wheat and barley were much lower (Edwards, 2009a, b, c; Edwards, 2012). Data from a three year commercial field survey (2009-2011) showed that $F$. langsethiae DNA as well as HT-2 and T-2 was highest in oats compared to wheat and barley (Opoku et al., 2013). In this field survey, the authors indicated that fields sampled, while in close proximity to one another (within $30 \mathrm{~km}$ ), they were grown under differing agronomy (eg sowing dates, rotations and chemical inputs). Agronomic factors are known to influence mycotoxins such as deoxynivalenol (DON), HT-2 and T-2 concentrations in cereal grains. For example oats sown after a cereal have a higher average concentration of HT-2 and T-2 in grains compared to oats 
sown after a non-cereal in a rotation (Edwards et al., 2009). The greater $F$. langsethiae infection (as indicated by high $F$. langsethiae DNA and HT-2+T-2 levels) in oats as compared to wheat and barley under commercial field conditions (Opoku et al., 2013) is not properly understood. Field experiments were therefore performed to determine if, under the same agronomic conditions, $F$. langsethiae DNA would be higher in oats than wheat and barley. Higher $F$. langsethiae DNA and subsequent high HT-2 and T-2 levels in oats compared to wheat and barley under identical agronomic conditions would suggest that the high infection rate of $F$. langsethiae and subsequent HT-2 and T-2 production in oats is more of an inherent host character and under the influence of genetic control rather than difference in the agronomy applied to the different cereal species. There are currently no known methods to successfully inoculate F. langsethiae under field conditions (Imathiu et al. 2013; Opoku 2012). Consequently field experiments were conducted using natural inoculum using fields that had intensive cereal rotations to increase the level of inoculum present. In a previous field survey (Opoku et al, 2013) where $F$. langsethiae infection was found to be higher in oats than in wheat and barley, DNA and mycotoxin analyses were performed on whole heads. For most agricultural systems however, cereals are threshed and the grains used as food or feed. It is important, therefore, to determine if threshed cereal grains are analysed a similar trend of results as in the field survey will be obtained.

The objectives of these experiments were therefore to determine the susceptibility of wheat, barley and oats to $F$. langsethiae infection under similar agronomic conditions and to compare the amount of $F$. langsethiae biomass (as measured by DNA) and HT-2+T-2 contained in threshed cereal grain and the rest of the cereal head.

\section{Materials and Methods}


Experiments were carried out on two different locations; Woodseaves located in Staffordshire, UK and Harper Adams University located in Shropshire, UK. Experimental sites were about $12 \mathrm{~km}$ apart. At each location two experiments were conducted within the same field, one for winter cereal varieties and the other for spring cereal varieties. Three varieties each of winter and spring wheat, barley and oats were selected based on their popularity within UK cereal production for use in the experiments (Table. 1). The experiment was laid out in a split plot design with cereal as the whole plot and the variety as the sub-plot. Each experiment comprised of four blocks with three whole plots which were divided into three sub-plots. Cereal species were randomized within each whole plot and the cereal variety randomised within each subplot.

Experiments were conducted after a crop of winter wheat in cereal intense rotations. Fields were ploughed and power harrowed just prior to sowing. Winter cereal varieties were sown in mid-October and spring varieties in mid-March using a plot drill (Plotman, Wintersteiger Austria). For winter cereal varieties a rate of 250 seeds $\mathrm{m}^{-2}$ was used for wheat and oats and $300 \mathrm{~m}^{-2}$ for barley. All spring cereal varieties were sown at 350 seeds $\mathrm{m}^{-2}$. The different seed rates were used to achieve a similar number of stems in late spring. Standard agronomic inputs were carried out on both fields based on a balance of the optimum agronomy for each cereal species. At maturity cereal heads were harvested manually and air dried after which they were threshed using a mini-threshing machine (F. Walter-H. Wintersteiger, Austria). Grains and the rest of the cereal heads (comprising of rachis, lemma and glume in wheat, the awns and the rachis in barley and rachis, rachis branches and the glumes in oats) were collected and milled in a sample mill (Cyclotec 1093).

\section{DNA extraction}


Milled samples were mixed thoroughly by hand and 5 and $3 \mathrm{~g}$ of milled grain and rest of cereal head samples, respectively, were weighed into $50 \mathrm{ml}$ centrifuge tubes for DNA extraction. To each $50 \mathrm{ml}$ centrifuge tube, $30 \mathrm{ml}$ of CTAB buffer $(87.7 \mathrm{~g} \mathrm{NaCl}, 23 \mathrm{~g}$ sorbitol, $10 \mathrm{~g} \mathrm{~N}$-lauryl sarcosine, $8 \mathrm{~g}$ hexadecyl trimethylammonium bromide, $7.5 \mathrm{~g}$ ethylenediamine tetraacetic acid and $10 \mathrm{~g}$ polyvinylpolypyrolidone, made up to $1 \mathrm{~L}$ with distilled water) were added. Tube contents were mixed thoroughly by hand and then with an Hs501 digital shaker (IKA Labortechnik) for 20 minutes and incubated at $65^{\circ} \mathrm{C}$ for 1 hour. Tubes were then shaken again by hand and centrifuged at 3,000 $\mathrm{x}$ g for 15 minutes after which $0.9 \mathrm{ml}$ of the supernatant was removed and added to $0.3 \mathrm{ml}$ potassium acetate $(5 \mathrm{M})$ in a sterile $1.9 \mathrm{ml}$ Eppendorf tube, mixed for 1 minute and frozen at $-20^{\circ} \mathrm{C}$ for 1 hour. Tube contents were thawed at room temperature before $0.6 \mathrm{ml}$ chloroform was added. The contents of the tubes were then mixed for $1 \mathrm{~min}$ and centrifuged at $12,000 \times \mathrm{g}$ for $15 \mathrm{~min}$. One milliliter of the aqueous phase was removed and added to a sterile $1.9 \mathrm{ml}$ Eppendorf tube containing $0.8 \mathrm{ml}$ of $100 \%$ isopropanol and mixed for $1 \mathrm{~min}$ before centrifuging at 12,000 x g for $15 \mathrm{~min}$. Resulting DNA pellets were washed twice with $1 \mathrm{ml} 44 \%$ isopropanol. Pellets were air dried before re-suspending in $0.2 \mathrm{ml} \mathrm{TE}$ buffer and incubating at $65^{\circ} \mathrm{C}$ for $25 \mathrm{~min}$. Tube contents were vortexed and left at room temperature overnight before spinning at $12,000 \mathrm{x} \mathrm{g}$ for $5 \mathrm{~min}$. DNA concentrations were determined using a Nanodrop 2000 spectrophotometer (Thermo Scientific, Basingstoke, UK). DNA extractions were diluted to $40 \mathrm{ng} \mu \mathrm{l}^{-1}$. After dilution, DNA concentrations were measured again to determine the final working concentration and stored at $4{ }^{\circ} \mathrm{C}$.

\section{Control PCR to determine the presence of amplifiable DNA in samples}

An initial control PCR was carried out on all DNA samples prior to quantitative PCR to ensure the presence and quality of DNA in samples. This involved amplification with ITS4 and ITS5 
These primers amplify both fungal and plant DNA present in a sample at an anneal temperature of $50^{\circ} \mathrm{C}$. PCR was carried out using a $25 \mu \mathrm{l}$ reaction mixture made up of $100 \mu \mathrm{M}$ of each nucleotide, $100 \mathrm{nM}$ of each primer, $20 \mathrm{U}$ of Taq polymerase (ABgene, Epsom, UK) $\mathrm{ml}^{-1}, 10$ $\mathrm{mM}$ Tris- $\mathrm{HCl}(\mathrm{pH} 8.3), 1.5 \mathrm{mM} \mathrm{MgCl}_{2}, 50 \mathrm{mM} \mathrm{KCl}, 100 \mu \mathrm{g}$ of gelatine $\mathrm{ml}^{-1}, 0.5 \mathrm{mg} \mathrm{ml}^{-1}$ of Tween $20,0.5 \mathrm{mg} \mathrm{ml}^{-1}$ of Nonidet P-40 and $5 \mu \mathrm{l}$ of DNA sample. PCR grade water was used as negative control. Samples were amplified using a PTC-100 thermal cycler (MJ Research Inc., Minnesota, USA) programmed for initial denaturation at $94^{\circ} \mathrm{C}$ for $75 \mathrm{~s}$ followed by 35 cycles of $15 \mathrm{~s}$ at $94^{\circ} \mathrm{C}, 15 \mathrm{~s}$ at $50^{\circ} \mathrm{C}$ and $45 \mathrm{~s}$ at $72^{\circ} \mathrm{C}$. There was a final extension step at $72^{\circ} \mathrm{C}$ for 4 min $25 \mathrm{~s}$ before cooling to $4^{\circ} \mathrm{C}$ until sample recovery. Amplicon gel electrophoresis was carried out on $2 \%$ agarose gels stained with ethidium bromide (0.05\%). PCR products (ca. 650 bp) were viewed on a Gel Doc 1000 system (Bio-Rad, Buckinghamshire, UK) under UV light.

Quantitative PCR to quantify Fusarium langsethiae DNA

DNA samples were amplified with a quantitative PCR instrument (iCycler Bio-Rad, UK) with F. langsethiae primers; FlangF3 5'-CAAAGTTCAGGGCGAAAACT-3'.and LanspoR1 5'TACAAGAAGACGTGGCGATAT-3' (Wilson et al., 2004) as detailed previously (Edwards et al., 2012). qPCR MasterMix Plus for $\mathrm{SYBR}^{\circledR}$ Green I with fluorescein (Eurogentec, USA) reagent was used according to manufacturer's instructions with a $25 \mu 1$ reaction volume which included $5 \mu$ l template DNA. PCR water $(5 \mu 1)$ was used instead of template as negative control. A 10 -fold dilution series of $F$. langsethiae DNA $\left(10^{0}-10^{-4} \mathrm{ng} \mu \mathrm{l}^{-1}\right)$ was included in each PCR run to provide a standard curve. Concentrations of $F$. langsethiae DNA were divided by the total DNA concentration within a sample to give values per ng of total DNA. min and an initial melt of $10 \mathrm{~min}$ at $95^{\circ} \mathrm{C}$ followed by 45 cycles with a melting step of $95^{\circ} \mathrm{C}$ 
146 for $10 \mathrm{~s}$, annealing temperature of $65^{\circ} \mathrm{C}$ for $10 \mathrm{~s}$, extension at $72^{\circ} \mathrm{C}$ for $30 \mathrm{~s}$, and a hold at $82^{\circ} \mathrm{C}$

147 for $10 \mathrm{~s}$ during which fluorescence was measured. Melting curve fluorescence was determined

148 by holding at $95^{\circ} \mathrm{C}$ for $1 \mathrm{~min}$, cooling to $55^{\circ} \mathrm{C}$ for $1 \mathrm{~min}$ and then raising the temperature to $14995^{\circ} \mathrm{C}$ at a ramp rate of $0.05^{\circ} \mathrm{C} \mathrm{s}^{-1}$.

HT-2+T-2 estimation

T-2 in milled cereal head sub-samples was measured using Ridascreen® T-2 ELISA assay (Rwas estimated based on the known ratio of HT-2 and T-2 in UK oats and the known crossreactivity of the T-2 antibody with HT-2 (Edwards et al., 2012).

Data analysis

Data was $\log _{10}$ transformed before analysis. Initial analysis of the data determined the winter sown experiments from the two locations had equivalent variance for both the DNA and mycotoxin concentrations and as such the data could be combined and analysed together. The same result was determined for the spring sown experiments which were also combined. Split plot ANOVA were carried out with block nested within location in the design structure and significant differences between means determined by LSD $(p=0.05)$ using Genstat (V.13 VSN International Ltd.) for both the winter and spring sown experiments. Regression analysis with groups (Genstat) was used to compare the relationship between $F$. langsethiae DNA and HT- 


\section{Fusarium langsethiae DNA recovered from cereal heads}

172 In general, levels of $F$. langsethiae DNA in oat heads were higher than in wheat and barley for both spring and winter varieties with levels ca. three times higher in winter oats compared to spring oats and only small differences between winter and spring sown wheat and barley (Table 2).

\section{Winter cereal species}

177 In winter cereal species, there was no significant interaction between cereal and cereal part (P $178=0.165)$. The interaction between cereal, variety and cereal part was also not significant $(\mathrm{P}=$ 179 0.778). It was observed that $F$. langsethiae DNA recovered from the rest of the cereal heads was significantly higher than that recovered from the grains $(\mathrm{P}<0.001) . F$. langsethiae DNA in the rest of the cereal heads was about fifteen times higher than that in the grains only with overall mean of 0.029 and $0.002 \mathrm{pg} \mathrm{ng}^{-1}$ respectively.

Fusarium langsethiae DNA recovered from the different varieties of wheat, barley and oat differed with a significant interaction between cereal and variety $(\mathrm{P}<0.001)$. For winter wheat, Alchemy had the highest $F$. langsethiae DNA which was significantly different from that recovered from Robigus but not Solstice (Fig. 1). Flagon had the highest $F$. langsethiae DNA among the winter barley varieties with a mean of $0.032 \mathrm{pg} \mathrm{ng}^{-1}$ and was significantly $(\mathrm{P}<0.05)$ different from that recovered from Cassia.(Fig 1). In winter oats, $F$. langsethiae DNA in heads of the different varieties were significantly $(\mathrm{p}<0.05)$ different from each other $($ Fig 1$)$ with that recovered from Gerald having the highest mean of $0.104 \mathrm{pg} \mathrm{ng}^{-1}$. 
In spring species, the interaction between cereal and cereal part was significant $(\mathrm{P}<0.001)$. In all three cereals $F$. langsethiae DNA in the rest of the head was significantly $(\mathrm{P}<0.05)$ higher than that in the grains. $\log _{10}$ transformed mean $F$. langsethiae DNA in the rest of the head was about 38 times higher than in the grains alone for wheat, eight times higher for barley and 17 times higher for oat (Fig. 2). The interaction between cereal and variety was significant $(\mathrm{P}<$ $0.001)$

In wheat, $F$. langsethiae DNA recovered from the different varieties were not significantly (P $>0.05$ ) different from each other (Fig. 3). For barley, Quench had a mean F. langsethiae DNA of $0.004 \mathrm{pg} \mathrm{ng}^{-1}$. This was the highest $F$. langsethiae DNA recovered from the spring barley varieties and was significantly $(\mathrm{P}<0.05)$ higher than that recovered from Propino which had the lowest mean $F$. langsethiae DNA of $0.0017 \mathrm{pg} \mathrm{ng}^{-1}$ (Fig 3). In oats, the highest $F$. langsethiae DNA was recovered from Firth with a mean $F$. langsethiae DNA of $0.23 \mathrm{pg} \mathrm{ng}^{-1}$ followed by that from Atego and Husky with mean F. langsethiae DNA of 0.004 and 0.002 pg $\mathrm{ng}^{-1}$ respectively. These means were all significantly $(\mathrm{p}<0.05)$ different from each other (Fig. $3)$.

\section{HT-2+T-2 concentration in cereal heads}

Levels of HT-2+T-2 in cereals followed similar patterns as for F. langsethiae DNA (Table 3).

\section{Winter cereal species}

In winter cereal species there was no significant interaction between cereal and cereal part $(\mathrm{P}=$ $0.059)$ and the interaction between cereal, variety and part was not significant $(\mathrm{P}=0.25)$. HT2+T-2 levels in different cereal parts analysed were different with the grains having significantly lower levels than that in the rest of the head $(\mathrm{P}<0.001)$. HT-2+T-2 levels in the 
rest of the head was about two times higher than that found in the grains with overall mean values of 206 and $115 \mu \mathrm{g} \mathrm{kg}^{-1}$ respectively.

Levels of HT-2+T-2 in the different winter cereal varieties differed with a statistically significant interaction between cereal and variety $(\mathrm{P}=0.001)$. Significant HT-2+T-2 difference was observed in winter oat varieties with mean values for Gerald, Mascani and Dalguise of 1956, 841 and $237 \mu \mathrm{g} \mathrm{kg}^{-1}$ respectively (Fig. 4). There were no significant (P > 0.05 ) differences in HT-2+T-2 concentration in the winter wheat or barley varieties (Fig. 4) with an overall mean HT-2+T-2 concentration of 159 and $154 \mu \mathrm{g} \mathrm{kg}^{-1}$ respectively.

A simple linear regression between $F$. langsethiae DNA recovered from winter cereal heads and their corresponding HT-2+T-2 grouped by cereal species showed a highly significant $(\mathrm{P}<$ 0.001) regression best fitted by separate non-parallel lines. However for wheat and barley alone a single line accounted for $68 \%$ of the variance and parallel lines although significant accounted for only an additional $1.5 \%$ of the total variance observed. Thus two lines where fitted, one for oat $\left(\mathrm{P}<0.001, \mathrm{r}^{2}=0.79\right)$ and another for wheat and barley $\left(\mathrm{P}<0.001, \mathrm{r}^{2}=0.68\right)($ Fig.5).

\section{Spring cereal species}

For HT-2+T-2 in spring cereal species, a significant $(\mathrm{P}<0.001)$ interaction was found between cereal species and cereal part. In spring wheat, HT-2+T-2 in the rest of the head was about three times higher than that found within the grains, whilst it was about one and half times higher in barley and about five times higher in oats (Fig. 6).

HT-2+T-2 levels in the different spring cereal varieties differed with a significant interaction between cereal and variety $(\mathrm{P}<0.001)$. In oats, the highest HT-2+T-2 concentration was recorded in Firth with a back-transformed mean of $433 \mu \mathrm{g} \mathrm{kg}^{-1}$. This was significantly $(\mathrm{p}<$ 0.05) higher than for Atego and Husky with a mean of 141 and $117 \mu \mathrm{g} \mathrm{kg}^{-1}$ respectively (Fig. 
7). HT-2+T-2 concentration in Quench was the highest among the three spring barley varieties $\left(71 \mu \mathrm{g} \mathrm{kg}^{-1}\right)$. This was significantly $(\mathrm{P}<0.05)$ higher than that for Propino $\left(55 \mu \mathrm{g} \mathrm{kg}^{-1}\right)$ which had the least HT-2+T-2 concentration among the three varieties (Fig.7). HT-2+T-2 concentration for the three spring wheat varieties were not significantly $(\mathrm{P}>0.05)$ different from each other (Fig. 7) with an overall back-transformed mean of $87 \mu \mathrm{g} \mathrm{kg}^{-1}$.

A simple linear regression between $F$. langsethiae DNA recovered from spring cereal heads and their corresponding HT-2+T-2 grouped by cereal species was highly significant $(\mathrm{P}<0.001)$ and was best fitted by separate non-parallel lines. However for wheat and barley alone, a single line account for $73 \%$ of the variance and parallel lines although significant accounted for only an additional $5.3 \%$ of the total variance observed. Thus two lines were fitted, one for oat $(\mathrm{P}<$ $\left.0.001, \mathrm{R}^{2}=0.78\right)$ and another for wheat and barley $\left(\mathrm{P}<0.001, \mathrm{R}^{2}=0.73\right)($ Fig.8). A visual comparison of Fig. 5 and 8 shows that the regressions for winter and spring oats were similar and the regression for winter and spring wheat and barley were nearly identical. Regression analysis was repeated for all oats grouped by sowing date (winter and spring). The data was best fitted by separate parallel lines (Fig. 9) which accounted for $84 \%$ of the observed variance. The regression plots shows that for a fixed concentration of $F$. langsethiae DNA there is a higher concentration of HT-2+T-2 on winter oats compared to spring. Regression analysis was also repeated for all barley and wheat samples grouped by sowing date. This regression showed sowing date had no significant effect on the relationship of HT-2+T2 to $F$. langsethiae DNA concentration and was best fitted by a single line $(y=0.024 x+2.45)$. The regression accounted for $64 \%$ of the observed variance. 


\section{Discussion}

This study has identified greater $F$. langsethiae infection and subsequent HT-2+T-2 contamination in oats compared to wheat and barley in both winter and spring sown cereals under controlled experimental conditions. This is consistent with observations from field surveys (Edwards et al., 2009; Opoku et al., 2013) and indicates that the differences observed during field surveys were primarily due to genetic differences between the cereal species rather than differences in the agronomy applied to these crops.

There was higher $F$. langsethiae DNA and HT-2+T-2 in winter sown compared to spring sown oats. This is in agreement with previous surveys (Edwards, 2012), however, as different varieties were sown in different experiments on different dates this can not be tested statistically, and it can not be determined if these differences are due to variety or sowing date. Only small differences were observed between winter and spring sown wheat and barley. This agrees with the three year UK survey data for winter and spring barley (Opoku et al., 2013) which showed in the year of this experiment there was little difference in the $F$. langsethiae levels between survey samples of winter and spring sown barley. Within the three years of the survey the difference between spring and winter barley were highly variable between seasons with higher levels in winter barley in 2009 and higher levels in spring barley in 2010 indicating weather during a key phenological period, such as flowering, maybe important. A three year survey of French barley found higher levels of HT-2+T-2 in spring compared to winter sown barley (Orlando et al., 2010) although it was not reported how consistent this was across the three years of the survey.

Results of this study have shown that a significant difference existed between $F$. langsethiae DNA and HT-2+T-2 levels in grains and the rest of the head with higher concentrations occurring in the rest of the cereal head compared to the grains. This would be expected as 
higher mycotoxin concentrations tend to occur in the outer layers/structures of cereal spikes compared to the grains (Edwards et al., 2009; Cowger and Arellano, 2013) and indicates that infection and mycotoxins production primarily occurs in the outer layers of the cereal head. There were significant differences for both DNA and HT-2+T-2 between the concentration in grains and the rest of the head for spring cereals but not winter cereals and the reasons for this are not clear. In general, the ratio was much higher for DNA (above 5-fold) compared to HT2+T-2 (ca. 2-fold). This shows there is not a consistent relationship between $F$. langsethiae DNA and HT-2+T-2 concentration at harvest across plant structures and this may be due to differences in production rates, translocation and or metabolism of the mycotoxins.

It is important to note that not only does $F$. langsethiae have a greater ability to infect oats, but the concentration of HT-2 and T-2 per unit fungal biomass is far higher in oats than the other two cereals. For example, in winter cereal varieties when the concentration of $F$. langsethiae DNA recovered from cereal heads is about $0.01 \mathrm{pg} \mathrm{ng}^{-1}$ the corresponding HT-2+T-2 concentration is about $100 \mu \mathrm{g} \mathrm{kg}^{-1}$ in both wheat and barley heads and about $250 \mu \mathrm{g} \mathrm{kg}^{-1}$ in oat heads. A ten-fold increase in $F$. langsethiae DNA concentration $\left(0.1 \mathrm{pg} \mathrm{ng}^{-1}\right)$ in cereal heads resulted in about a $50 \%$ increase in HT-2+T-2 concentration $\left(150 \mu \mathrm{g} \mathrm{kg}^{-1}\right)$ in wheat and barley and a $400 \%$ increase $\left(1000 \mu \mathrm{g} \mathrm{kg}^{-1}\right)$ in winter oat heads. The reasons for these observed differences are not clear, however, there is evidence that some plant species are able to metabolise trichothecenes. For example Lemmens et al. (2005) reported that the resistance of a wheat genotype (CM82036) to FHB and DON was due to its ability to convert DON to DON3-glucoside, a less toxic derivative. The possibility thus exists that the observed relatively lower HT-2+T-2 concentration in wheat and barley heads per unit $F$. langsethiae DNA compared to oats could be due to a greater ability of wheat and barley to metabolise HT-2 and T-2. Recently researchers have identified numerous plant metabolites of HT-2 and T-2 in wheat, barley and oats (Nathanail et al., 2015; Meng-Reiterer et al., 2016; Veprikova et al., 2012). A greater 
proportion of glucoside metabolites compared to the parent mycotoxins were found in wheat compared to oats (Lattanzio et al., 2012). Indicating wheat may have a greater ability to metabolise HT-2 and T-2 compared to oats. Nathanail et al. (2015) showed that HT-2 and T2 are rapidly metabolised by wheat with less than $15 \%$ of the original parent molecule remaining at harvest after addition of the mycotoxins during flowering. It could also be that the oat head provides certain conditions that stimulate greater HT-2 and T-2 production. The higher HT-2+T-2 concentration per unit of $F$. langsethiae in winter compared to spring oats may be due to either the genetic differences between varieties or due to the fact that winter oats develop earlier with heads emerging earlier than spring oats. This means that panicles of winter sown oats are exposed to $F$. langsethiae infection earlier and for a longer period allowing for more HT-2 and T-2 production compared to spring oats. This assumption however, does not hold for wheat and barley since little differences were seen between winter and spring sown varieties for these species.

This study has confirmed the preference of $F$. langsethiae for oats and the subsequent production of high HT-2 and T-2 in oat heads even when wheat, barley and oats are cultivated under the same agronomic conditions. Not only are oats more susceptible to $F$. langsethiae compared with the other cereal species but they also accumulate more HT-2+T-2 compared to other cereal species per unit of $F$. langsethiae biomass.

Acknowledgement The first author acknowledges funding of a $\mathrm{PhD}$ studentship from Harper Adams University and AHDB Cereals and Oilseeds (RD-2008-3479).

\section{Compliance with ethical standards}


Conflict of interest The authors declare that they have no conflict of interest.

\section{References}

Anon (2013). Commission Recommendation on the presence of T-2 and HT-2 toxin in cereals and cereal products Official Journal of the European Union, L91, 12-15.

Cowger C, Arellano C, 2013. Fusarium graminearum infection and deoxynivalenol concentrations during development of wheat spikes. Phytopathology 103, 460-471.

Edwards SG, 2009. Fusarium mycotoxin content of UK organic and conventional barley. Food Additives and Contaminants 26, 1185-1190.

Edwards SG, 2012. Improving risk assessment to minimise Fusarium mycotoxins in harvested oats and malting barley. HGCA Project Report No. RD-2007-3332, HGCA, London.

Edwards SG, 2007. Investigation of Fusarium mycotoxins in UK barley and oat production. HGCA Project Report No. 415. HGCA, London.

Edwards SG, Barrier-Guillot B, Clasen PE, Hietaniemi V, Pettersson H, 2009. Emerging issues of HT and T-2 toxins in European cereal production. World Mycotoxin Journal 2, 173-179.

Edwards SG, Imathiu S, Ray RV, Back M, Hare CM, 2012. Molecular studies to identify the

347 Fusarium species responsible for HT-2 and T-2 mycotoxins in UK oats. International Journal of Microbiology.156. 168-175

Imathiu, S. M., Edwards, S. G., Ray, R. V., \& Back, M. A. (2013). Fusarium langsethiae - a HT-2 and T-2 toxins producer that needs more attention. Journal of Phytopathology, 161(1), 1-10, doi:10.1111/jph.12036. 
Lattanzio VM, Visconti A, Haidukowski M, Pascale M, 2012. Identification and characterization of new Fusarium masked mycotoxins, T2 and HT2 glycosyl derivatives, in naturally contaminated wheat and oats by liquid chromatography-high-resolution mass spectrometry. Journal of Mass Spectrometry 47, 466-475.

Lemmens M, Scholz U, Berthiller F, Dall' Asta C, Koutnik A, Schuhmacher R, Adam G, Buerstmayr H, Mesterha'zy A, Krska R, 2005. The ability to detoxify the mycotoxin deoxynivalenol colocalizes with a major quantitative trait locus for Fusarium head blight resistance in wheat. Molecular Plant-Microbe Interactions 18, 1318-1324.

Meng-Reiterer J, Bueschl C, Rechthaler J, Berthiller F, Lemmens M, Schuhmacher R, 2016. Metabolism of HT-2 Toxin and T-2 Toxin in Oats. Toxins 8, 364.

Nathanail AV, Varga E, Meng-Reiterer J, et al., 2015. Metabolism of the Fusarium Mycotoxins T-2 Toxin and HT-2 Toxin in Wheat. Journal of Agricultural and Food Chemistry 63, 78627872.

Opoku N, 2012. Study of Fusarium langsethiae infection in UK cereals. A PhD thesis submitted to the Harper Adams University, Shropshire, UK.

Opoku N, Back M, Edwards SG, 2013. Development of Fusarium langsethiae in commercial cereal production. European Journal of Plant Pathology 136, 159-170.

Orlando B, Barrier-Guillot B, Gourdain E, Maumene C, 2010. Identification of agronomic factors that influence the levels of T-2 and HT-2 toxins in barley grown in France. World Mycotoxins Journal 3, 169-174.

Veprikova Z, Vaclavikova M, Lacina O, Dzuman Z, Zachariasova M, Hajslova J, 2012. Occurrence of mono- and di-glycosylated conjugates of T-2 and HT-2 toxins in naturally contaminated cereals. World Mycotoxin Journal 5, 231-240. 
375 Wilson, A, Simpson D, Chandler E, Jennings P, Nicholson, P, 2004. Development of PCR 376 assays for the detection and differentiation of Fusarium sporotrichioides and Fusarium 377 langsethiae. Microbiology Letters, 233, 69-76.

378

379

380

381

382

383

384

385 
387 Table 1. Winter and spring varieties of wheat, barley and oats used within the autumn and spring sown experiments respectively

Variety (sub-plot)

Cereal (whole plot)

Winter varieties

Spring varieties

Wheat variety 1

Alchemy

Belvoir

Wheat variety 2

Robigus

Paragon

Wheat variety 3

Solstice

Granary

Barley variety 1

Cassia

Propino

Barley variety 2

Flagon

Quench

Barley variety 3

Suzuka

Tipple

Oats variety 1

Dalguise

Firth

Oats variety 2

Gerald

Atego

Oats variety 3

Mascani

Husky 
391 Table 2. Whole plot (cereal species) ANOVA mean values and statistical values for $\log _{10}$ 392 transformed $F$. langsethiae DNA concentrations $\left(\mathrm{pg} \mathrm{ng}^{-1}\right)$ for heads of wheat, barley and oat at 393 harvest. Back transformed data in parentheses.

\section{F. langsethiae DNA $\left(\mathrm{pg} \mathrm{ng}^{-1}\right)$}

\begin{tabular}{|c|c|c|}
\hline & Winter varieties & Spring varieties \\
\hline Wheat & $-2.371(0.0043)$ & $-2.420(0.0037)$ \\
\hline Barley & $-2.762(0.0017)$ & $-2.597(0.0025)$ \\
\hline Oat & $-1.754(0.0176)$ & $-2.239(0.0058)$ \\
\hline P-value & $<0.001$ & 0.01 \\
\hline$\% \mathrm{CV}$ & 7.1 & 8.4 \\
\hline $\operatorname{LSD}(5 \%)$ & 0.176 & 0.234 \\
\hline
\end{tabular}

394

395

396 
Table 3. Whole plot (cereal species) ANOVA mean values and statistical values for $\log _{10^{-}}$ transformed HT-2+T-2 concentrations $\left(\mu \mathrm{g} \mathrm{kg}^{-1}\right)$ in heads of wheat, barley and oats at harvest.

400 Back-transformed data in parentheses.

HT-2+T-2 $\left(\mu \mathrm{g} \mathrm{kg}^{-1}\right)$

\begin{tabular}{|c|c|c|}
\hline & Winter cereals & Spring cereals \\
\hline Wheat & $1.910(81)$ & $1.865(73)$ \\
\hline Barley & $1.790(62)$ & $1.792(62)$ \\
\hline Oat & $2.905(804)$ & $2.285(193)$ \\
\hline P-value & $<0.001$ & 0.04 \\
\hline$\% \mathrm{CV}$ & 2.5 & 3.4 \\
\hline LSD & 0.24 & 0.29 \\
\hline
\end{tabular}

401

402

403 


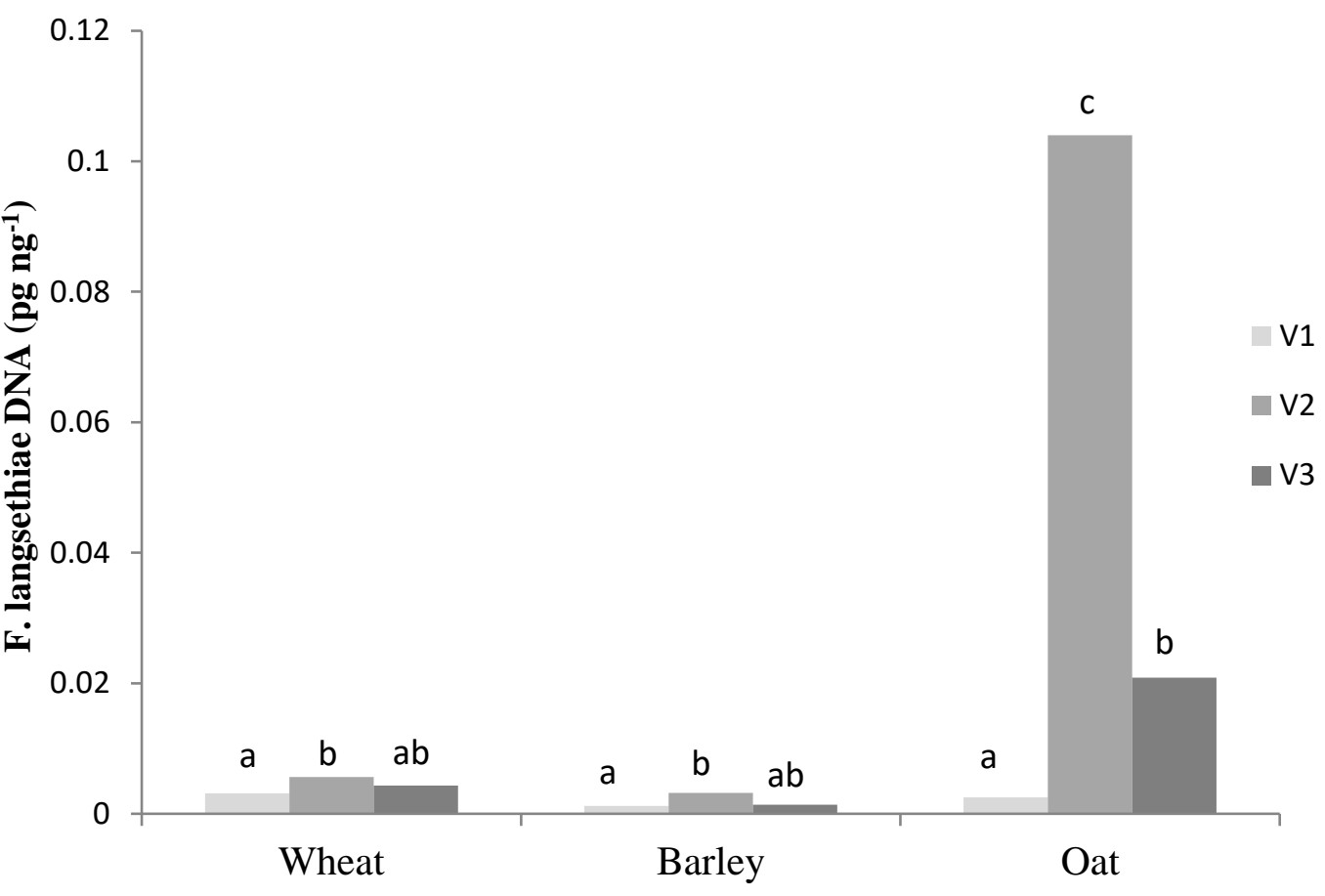

405 Figure 1. Back-transformed $F$. langsethiae DNA recovered from the different winter cereal 406 varieties. For wheat V1 = Alchemy, V2 = Robigus and V3 = Solstice. For barley V1 = Cassia, 407 V2 = Flagon and V3 = Suzuka. For oat V1 = Dalguise, V2 = Gerald and V3 = Mascani. 408 Varieties of the same cereal species with the same letter are not statistically different from each 409 other LSD, $\mathrm{P}=0.05$ ).

410

411

412

413 


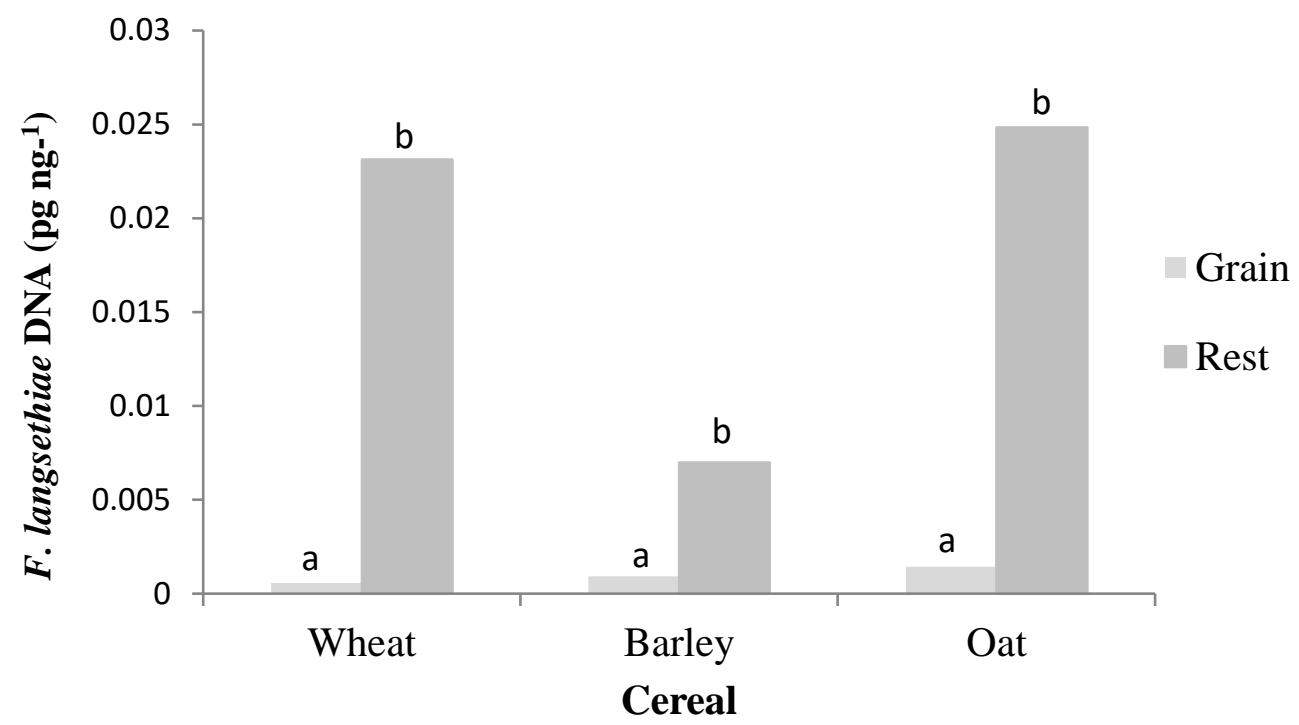

415 Figure 2. F. langsethiae DNA recovered from grains and the rest of the heads of spring wheat barley and oats. Parts of cereal for each species with the same letter are not statistically different 417 from each other (LSD, $\mathrm{P}=0.05$ ).

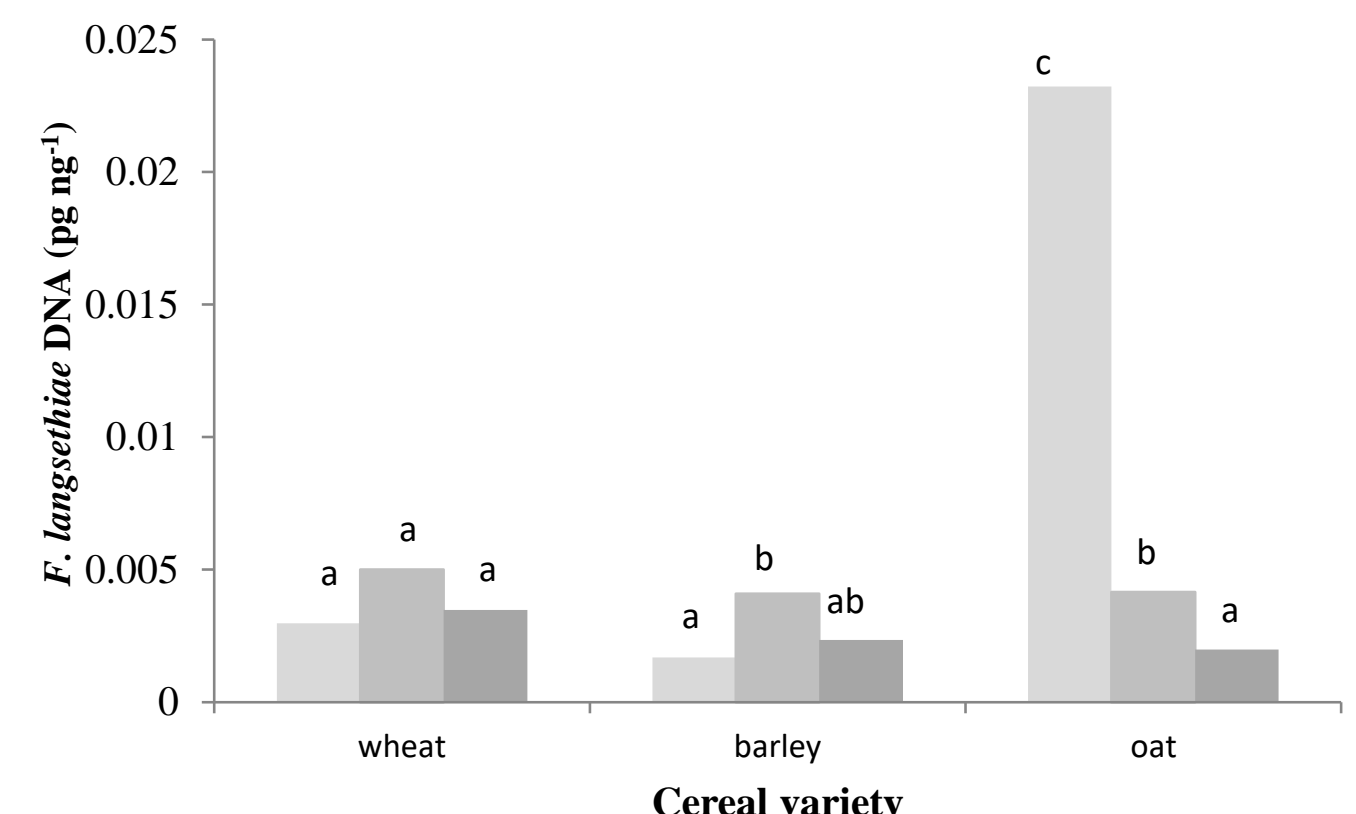

Figure 3. Back-transformed mean $F$. langsethiae DNA recovered from the different spring cereal varieties. For wheat V1 = Belvoir, V2 = Paragon and V3 = Granary. For barley V1 = Propino, V2 = Quench and V3 = Tipple. For oat V1 = Firth, V2 = Atego and V3 = Husky. Varieties of the same cereal species with same letter are not statistically different from each other (LSD, $\mathrm{P}=0.05$ ) 


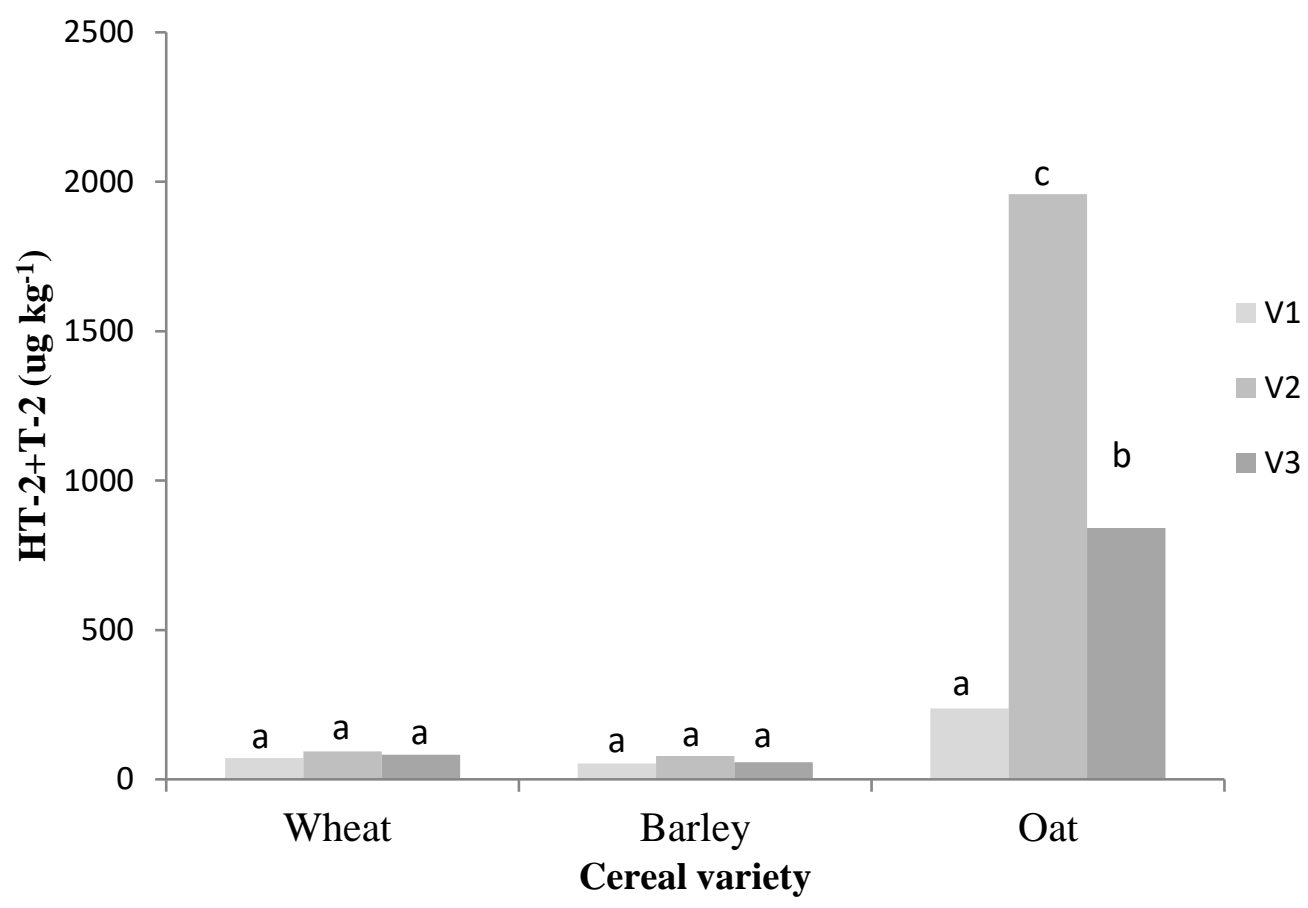

428 Figure 4. HT-2+T-2 levels in the different winter cereal varieties. For wheat V1 = Alchemy, 429 V2 = Robigus and V3 = Solstice. For barley V1 = Cassia, V2 = Flagon and V3 = Suzaka. For oat V1 = Dalguise, V2 = Gerald and V3 = Mascani. Varieties of the same cereal species with same letter are not statistically different from each other (LSD, $\mathrm{p}=0.05)$

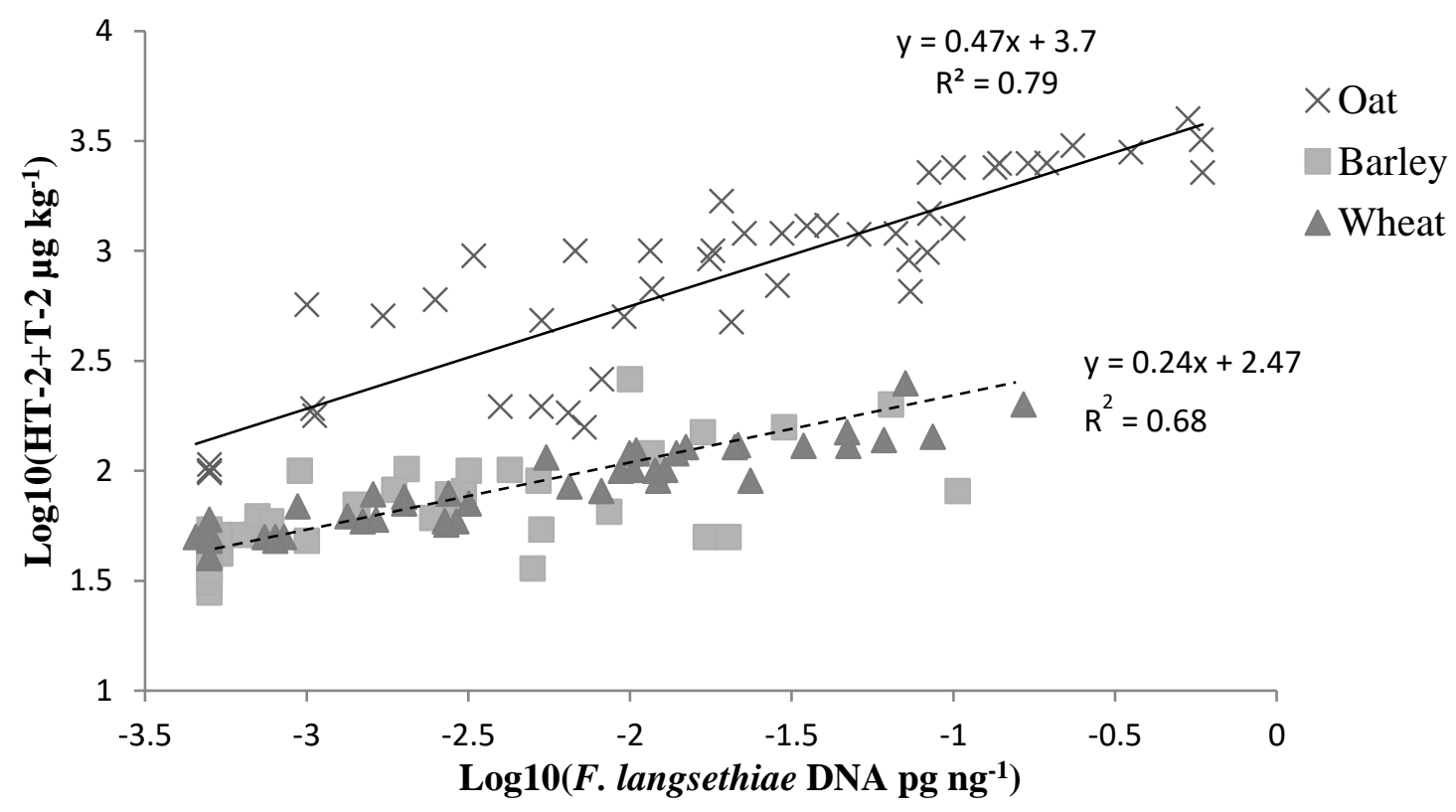

Figure 5. The relationship between $F$. langsethiae DNA and HT-2+T-2 concentration in winter cereal heads. 


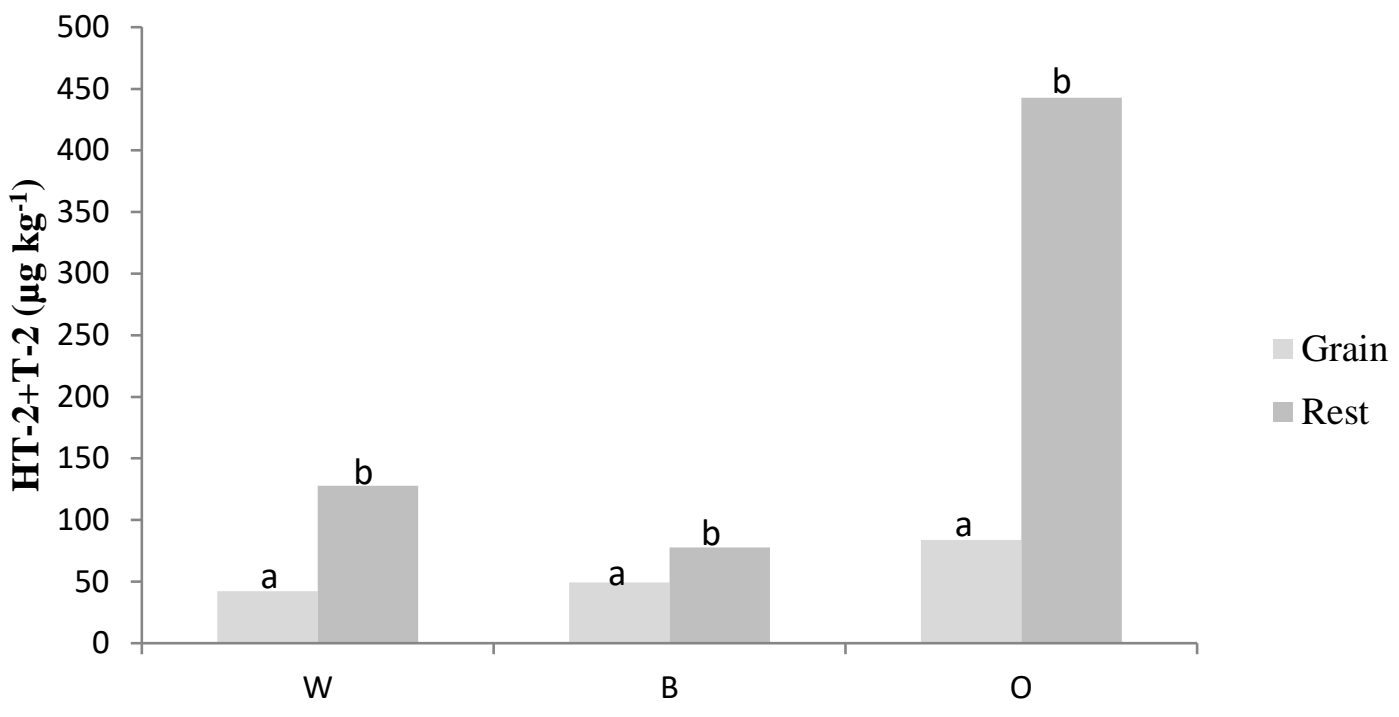

Cereal part

440 Figure 6. Back-transformed HT-2+T-2 concentration for grains and the rest of the heads of spring wheat, barley and oats. For each cereal species parts of cereal with the same letter are not statistically different from each other (LSD, $\mathrm{p}=0.05)$ )

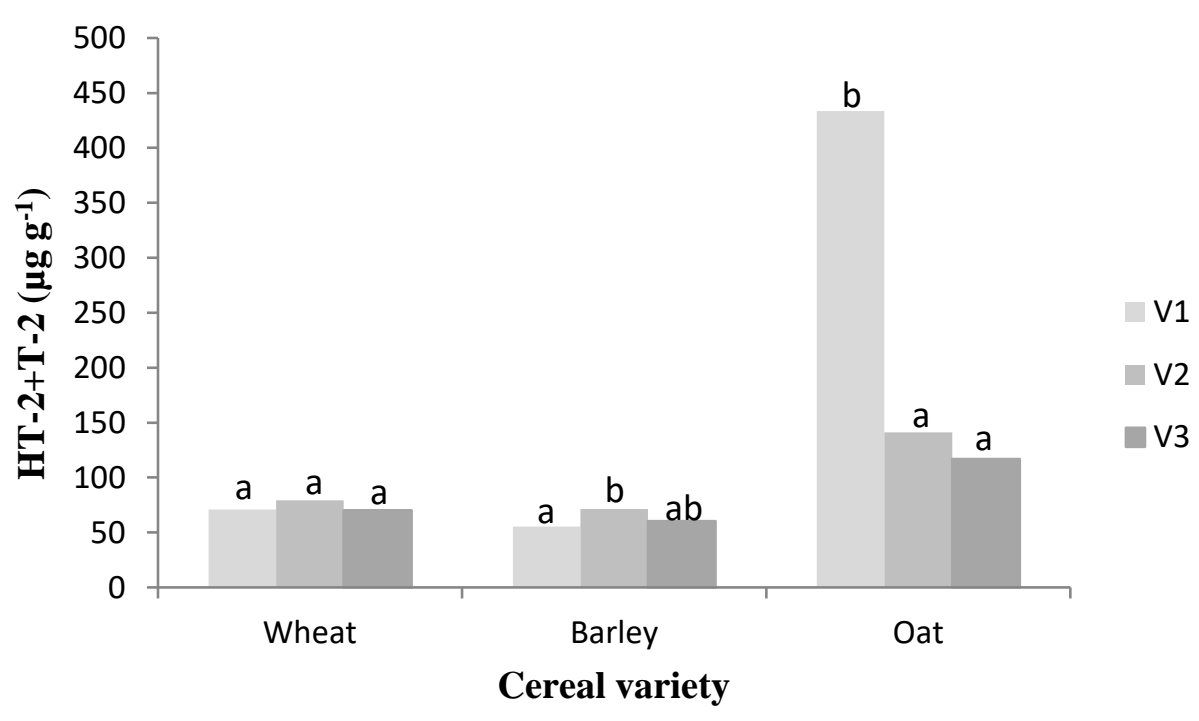

447 Figure 7. Back-transformed HT-2+T-2 levels in the different spring cereal varieties. For wheat, 448 V1 = Belvoir, V2 = Paragon and V3 = Granary. For barley V1 = Propino, V2 = Quench and 449 V3 = Tipple. For oat V1 = Firth, V2 = Atego and V3 = Husky. Varieties of the same cereal 450 species with same letter are not statistically different from each other (LSD, $\mathrm{P}=0.05$ ). 


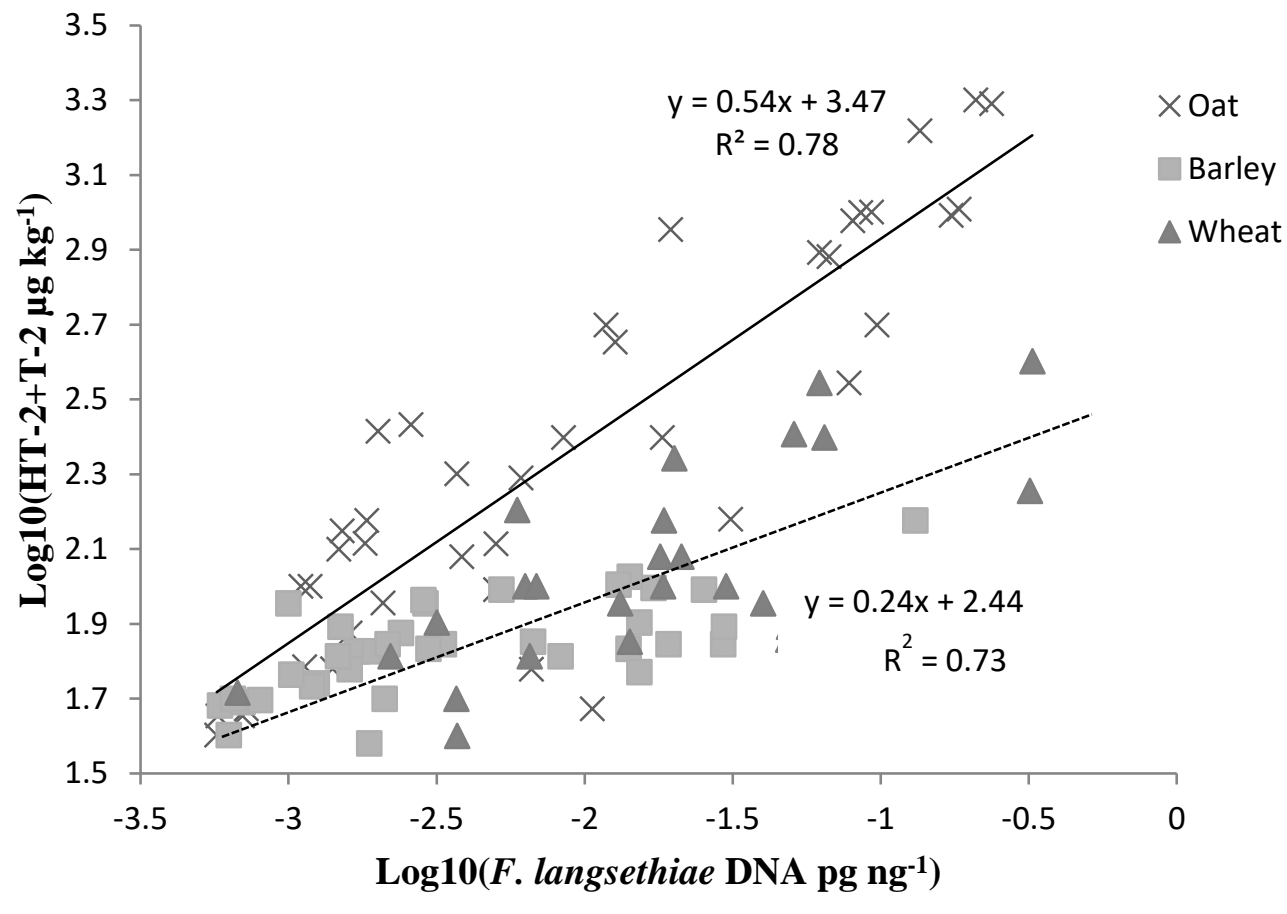

454 Figure 8. Relationship between $F$. langsethiae DNA and HT-2+T-2 concentration in spring 455 cereal heads.

456

457 


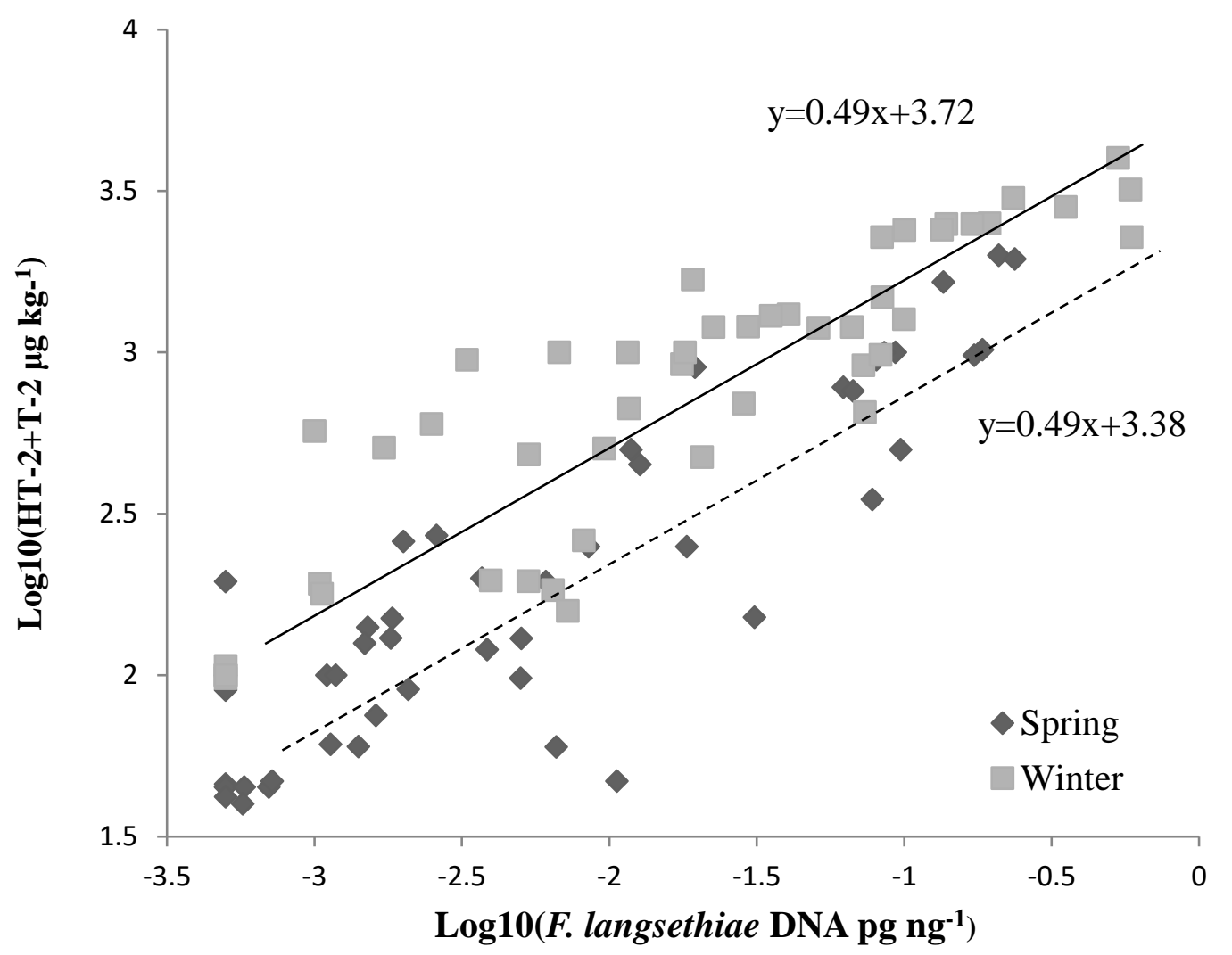

458

459 Figure 9. Relationship between $F$. langsethiae DNA and HT-2+T-2 concentration in winter 460 and spring sown oats. 